\title{
Nanduty
}

ISSN:2317-8590

\section{CONTRIBUIÇÕES A PARTIR DA BIOPOLÍTICA PARA A COMPREENSÃo DA GOVERNAMENTALIDADE NOS ESTÁDIOS DE FUTEBOL}

\section{CONTRIBUTIONS FROM BIOPOLYTICS FOR THE UNDERSTANDING OF GOVERNMENTALITY IN FOOTBALL STADIUMS}

\author{
Vinícius Teixeira Pinto (PPGAS/UFRGS) - viniciustxp@ gmail.com
}

\begin{abstract}
Resumo: Este ensaio apresenta algumas das contribuições de Michel Foucault a partir da introdução do conceito de biopolítica em sua obra no desenrolar dos anos 1970. O principal propósito aqui é o de refletir sobre o que esta categoria aporta, além de demarcar sua diferença em relação à noção de poder soberano. Posteriormente, o esforço pretendido será o de aproximar este referencial teórico dos problemas e das discussões atuais sobre futebol, torcidas organizadas, públicos, estádios e governamentalidade na antropologia. Com isso, espero questionar a pertinência dos conceitos enquanto esboço a possibilidade de pensá-los no processo de arenização dos estádios de futebol no Brasil em conjunto às transformações nas formas de governo dos públicos.
\end{abstract}

Palavras-chave: Governamentalidade; Biopolítica; Arenização; Torcidas de futebol.

\begin{abstract}
This essay discusses some of Michel Foucault's theoretical contributions since the introduction of the concept of biopolitics in his work in the late 1970s. For now, the main purpose is to reflect on what this category contributes as well as to demonstrate its difference in comparision to the concept of sovereign power. This work aims to bring together this theoretical reference to the problems and the current discussions about football, "torcidas organizadas" (associated football fans), audience, stadiums and governmentality in contemporary Brazil. Thus, it will be possible to ponder about its relevance on the process of modernization of local football stadiums, which is taking place alongside transformations in the ways of government of their publics.
\end{abstract}

Keywords: Governmentality; Biopolitics; “Arenização”; Football fans. 


\section{Nanduty}

ISSN:2317-8590

Muitas das abordagens da obra de Foucault estiveram mais relacionadas aos textos referentes ao poder disciplinar, especialmente àquele definido em Vigiar e Punir, trabalho inicialmente publicado em 1975. Estas leituras sobre instituições totais e disciplina dos corpos talvez sejam as mais conhecidas do autor e, por consequência, ofuscaram o desenvolvimento posterior de sua obra, onde aparecem temas e conceitos como governamentalidade, biopoder, biopolítica e população. Neste espaço, buscarei fazer uma reflexão sobre as transformações desencadeadas em seu pensamento a partir da segunda metade da década de 1970, especialmente depois da publicação de seus cursos no Collège de France.

Uma das ideias introduzidas sobre poder na segunda fase de Foucault é a sua percepção de outras formas de controle e de disciplina, não mais monopolizadas pelas instituições totais. São dispositivos do governo de si, internalizados, que normalmente dispensam ou coexistem com tecnologias externas de disciplina, revelando outras formas de agenciamento para além da forma institucional.

Neste ensaio, espero, portanto, refletir sobre as possibilidades de uso destes referenciais conceituais relativos à biopolítica no caso dos torcedores de futebol no atual contexto dos novos estádios e arenas ${ }^{1}$. A hipótese debatida aqui, a partir do conjunto de conceitos proposto, compreende que, nestes estádios de futebol, há uma nova governamentalidade que demanda a ressubjetivação dos públicos. Após a arenização dos estádios para a Copa do Mundo FIFA, novos protocolos de gestão dos eventos esportivos têm sido seguidos. Neles, desencoraja-se o confinamento dos torcedores. Em vez disso, os espaços agora individualizados sugerem um público não massificado. Conjuntamente a isso, atuaria ainda um processo histórico de comodificação do esporte, que poderia ser percebido também como elitização desses espaços. Caso essa hipótese seja aceita, seria possível afirmar, aproveitando a obra de Foucault, que o futebol de

\footnotetext{
1 Aqui, o conceito de biopolítica é entendido como o momento histórico em que se busca "(...) racionalizar os problemas colocados para a prática governamental pelos fenômenos próprios de um conjunto de viventes enquanto população" (Castro 2009: 58-59), portanto conjunto de técnicas e conhecimentos para governo de população. Esse poder se ocupa dos nascimentos, enfermidades, velhice, etc. Para os fins desse ensaio, interessa sua faceta voltada às relações com o espaço e a cidade.
} 


\section{Nanduty}

ISSN:2317-8590

espetáculo contemporâneo demanda - ou tenta fomentar - um espectador capaz de se responsabilizar por si mesmo.

O conceito de biopoder aparece para dar conta de uma mudança na natureza do governo, anteriormente sobre o direito de matar e deixar viver, posteriormente deslocado para o poder de fazer viver e deixar morrer. O primeiro destes modelos conforma a característica principal do poder soberano, cujo objeto do exercício é o território. O súdito, consequentemente, tem seu direito de vida e morte - assim como seu estatuto político - atrelado e dependente da vontade soberana do governante. É precisamente por poder matar que o soberano tem garantido seu direito sobre a vida do súdito (Foucault 2010: 202). Sem necessariamente exterminar esse direito, desenvolvese no século XIX, de acordo com Michel Foucault (2010: 202), um “direito novo que não vai apagar o primeiro, mas vai penetrá-lo, perpassá-lo, modificá-lo, e que vai ser um direito exatamente inverso: poder de 'fazer' viver e de 'deixar' morrer" .

Segundo a formulação de Foucault, a nova relação estabelecida é de complementaridade. $\mathrm{O}$ biopoder não extingue o poder soberano, mas produz modificações importantes. Na biopolítica, o autor considera que "o direito de morte tenderá a se deslocar ou, pelo menos, a se apoiar nas exigências de um poder que gere a vida $(\cdots)$ " , e prossegue, “esse formidável poder de morte $(\cdots)$ apresenta-se agora como o complemento de um poder que se exerce, positivamente, sobre a vida, que empreende sua gestão, sua majoração $(\cdots)$. As guerras já não se travam em nome do

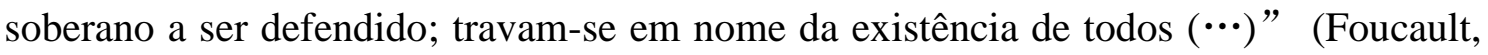
2017: 146-147). Esta nova fundamentação sobre o direito de morte - em favor da manutenção da vida, não mais do soberano - demandará também uma nova ciência do governo.

A passagem da morte para a vida nos reporta a um debate que terá aparecido no século XVI sobre as características do governo e daquilo que se governa. Em $O$ príncipe (primeira publicação em 1532), de Maquiavel, Foucault (2016: 407-410) identifica que o governante é postulado enquanto exterior ao objeto governado. Este seria tão somente 


\section{Nanduty}

ISSN:2317-8590

o principado, o território. Em uma literatura posterior denominada "anti-maquiavel”, objeta-se que "também se diz governar uma casa, almas, crianças, uma província, um convento, uma ordem religiosa, uma família” (La Perrière apud Foucault, 2016: 411), indicando outros alvos da arte de governar. Segundo a interpretação de Foucault (2016: 412-415), estes textos manifestam a percepção de formas de governo concernentes à moral, à política e à economia, demonstrando um sentido muito mais amplo do que aquele indicado no clássico $O$ príncipe. A relevância, do ponto de vista da biopolítica, é precisamente este deslocamento: “a definição do governo não se refere de modo algum ao território. Governam-se coisas”, e, acrescenta-se, “um conjunto de homens e coisas” (Foucault, 2016: 415).

O biopoder - que não exclui o poder soberano, mas o subjuga nesta nova configuração - tem por princípio a gestão de "homens e coisas" , a gestão da vida (o que é muito diferente da simples gestão do território). No primeiro volume de História da sexualidade, definem-se “dois polos” não excludentes do desenvolvimento do poder sobre a vida. O primeiro deles seria o corpo; o segundo, a população. Desenvolvem-se, a partir do século XVII, técnicas específicas para a administração destes alvos do governo. Primeiramente, uma anatomo-política que terá por objetivo o adestramento e a fabricação de corpos individuais por instituições disciplinares. Posteriormente, conhecimentos relativos à demografia para intervenções através de processos econômicos, políticas de higienização e outros, incidindo sempre sobre um corpo generalizado: o da população (Foucault, 2017: 149-152).

A obra de Foucault deu grande atenção à anatomo-política. Entendo que as instituições disciplinares poderiam ser caracterizadas por assumirem uma responsabilidade totalizante sobre os corpos a serem individualizados, operando a partir de uma racionalidade, que também poderíamos denominar “razão de Estado" . Gilles Deleuze (1992: 219) destaca que, na sociedade disciplinar - cujo melhor exemplo seria a primeira metade do século XX - , “o indivíduo não cessa de passar de um espaço fechado a outro, cada um com suas leis: primeiro a família, depois a escola $(\cdots)$, depois a caserna $(\cdots)$, depois a fábrica, de vez em quando o hospital, eventualmente a prisão $(\cdots)$ ” . A característica principal das instituições fechadas é que ao estar imerso em 


\section{Nanduty}

ISSN:2317-8590

uma, não é possível estar simultaneamente em outra. Todas as rotinas, todas as atividades, serão determinadas pela instituição responsável pelo indivíduo.

O argumento de Deleuze neste texto é o de que estaríamos passando, a partir da segunda metade do século XX, a uma sociedade predominantemente de controle, onde as instituições fechadas se tornam porosas e não necessariamente provedoras do indivíduo em sua totalidade: "Por exemplo, na crise do hospital como meio de confinamento, a setorização, os hospitais-dia, o atendimento a domicílio puderam marcar de início novas liberdades, mas também passaram a integrar mecanismos de controle que rivalizam com os mais duros confinamentos” (Deleuze 1992). Neste contexto, o indivíduo deve operar dentro de uma lógica mais próxima daquela do homo ecomonicus liberal, cuja orientação advém do cálculo racional, não mais realizado pelo Estado, mas pelo próprio sujeito governado (Foucault, 2008: 398-399; 401-402; 422423). Este, num plano ideal, não pode mais esperar que as antigas instituições disciplinares façam a gestão de si. Ao contrário, deve se comportar como indivíduoempreendedor, autônomo e capaz de gerir seus recursos de forma adequada para satisfazer suas necessidades ${ }^{2}$.

Acredito que os conceitos desenvolvidos a partir do referencial da biopolítica possam contribuir para pensar o caso das torcidas de futebol em um contexto de reformulação dos estádios e crescente comodificação do esporte. Sem tirar conclusões precipitadas e sabendo da necessidade de pesquisas mais detalhadas, especulo agora sobre um cenário que pode indicar algumas transformações.

Neste sentido, o primeiro interesse a respeito das torcidas de futebol se refere aos governos destas. Inicialmente, interessa-me pensar, tanto no nível do corpo quanto da

\footnotetext{
Há uma linha argumentativa que defende que, em $O$ nascimento da biopolíitca, Foucault teria se aproveitado em alguma medida da racionalidade neoliberal exatamente por sua crítica à razão de Estado. Por sua "fobia de Estado" , os liberais ofereceriam um contraponto ao sujeito do direito, entendido enquanto sujeito negativo pois renúncia a si, bem como à sua razão (cf. Lagasnerie 2013/4). É preciso dizer, no entanto, que tal perspectiva é tão controversa quanto atípica. Como contraponto, argumenta-se que a única razão que Foucault identifica no neoliberalismo é a do crescimento econômico (cf. Corbanezi 2014). Há também a leitura de que Foucault assume uma posição tão somente analítica - e não prescritiva - sobre os acontecimentos discursivos do liberalismo (cf. Avelino 2016).
} 


\section{Nanduty}

ISSN:2317-8590

população (aproveitando a terminologia do referencial da biopolítica), como os novos e caríssimos estádios construídos nos anos que antecederam a Copa do Mundo FIFA, realizada em 2014 no Brasil, provocaram rearranjos da subjetividade torcedora no futebol de espetáculo. Em seguida, deveríamos questionar quais teriam sido impactos mais amplos provocados pela introdução destes estádios e suas tecnologias de governo no contexto das cidades.

Como é sabido, as novas arquiteturas das arenas de futebol remodelaram estádios antigos ou inspiraram a construção de novos. Em tese, as mudanças no projeto visavam oferecer maior conforto tanto ao público quanto aos profissionais que trabalham em uma partida de futebol. Entre as principais transformações, é possível elencar a substituição das arquibancadas por cadeiras individuais, assim como uma maior proximidade dos espectadores para o campo de jogo, ao mesmo tempo em que são retirados os obstáculos físicos (alambrados, grades, fossos) que, no modelo anterior, serviam para impedir eventuais tumultos provocados por invasões de campo por parte dos torcedores.

Este formato foi denominado all-seated (todos sentados) e começou a ser implementado na Inglaterra dos anos 1980 e 1990, época na qual a preocupação sobre o governo dos torcedores de futebol se tornou explícita. O famoso “Desastre de Hillborough $^{3}$ ”, que, graças à superlotação, provocou a morte de 96 pessoas em um estádio, motivou investigações e culminou em um relatório, o “Taylor Report” , em que se atribuía esta tragédia a uma série de fatores: a má condição dos estádios, os maus-tratos aos torcedores (sendo sempre pensados enquanto transgressores), $\mathrm{o}$ alcoolismo (que inclinaria a comportamentos violentos), o hooliganismo (espetáculo criado a partir da necessidade de conter os torcedores violentos), omissão dos clubes de futebol, entre outros (Alabarces 2012).

Os antigos estádios eram entendidos como “precários” , “desconfortáveis” e “perigosos”, pois não impediam as aglomerações, suas acomodações não eram individualizadas, tinham más condições de higiene e, sobretudo, reuniam pessoas “perigosas”, “violentas” ou então “inclinadas à violência” . Os novos estádios

\footnotetext{
Ver "What happened at Hillborough in 1989?" em https://www.telegraph.co.uk/news/0/happened-hillsborough-1989/ (acessado em 01/08/2018).
} 


\section{Nanduty}

ISSN:2317-8590

foram implementados de forma generalizada no futebol inglês na década de 1990, utilizando-se da justificativa da segurança e do conforto.

Pensando esse exemplo com base no governo dos torcedores, pode-se buscar referenciais nas ideias de Foucault. A reconfiguração do espaço, a exigência de manterse sentado, assim como a demarcação de lugares individuais através das cadeiras, remetem diretamente às políticas que fabricam corpos. A supressão das barreiras que separam os torcedores do gramado se justificou pela garantia da segurança, especialmente depois do episódio Hillborough, que poderia ter sido evitado caso os torcedores não houvessem sido esmagados contra os alambrados.

Em substituição a estas tecnologias, surgiram outras. As grades deram lugar às câmeras de monitoramento e aos sistemas de registro e identificação. Ao contrário das antigas técnicas, estas devem permitir a punição individualizada ao eventual torcedor/infrator.

Esta aproximação, através do referencial foucaultiano, não é inédita. Gaffney \& Mascarenhas (2005/06) inicialmente pensam os estádios a partir de fatores históricos e geográficos, salientando suas significações materiais. Posteriormente os autores descrevem algumas das transformações nos estádios brasileiros logo no princípio do século XXI, antes ainda da candidatura do Brasil para sede da Copa do Mundo FIFA. Neste ponto, eles afirmam perceberem uma crescente disciplinarização dos estádios, sugerindo que estes espaços poderiam ser lidos na mesma chave analítica que escolas, hospitais e prisões, visto que, segundo esta abordagem, organizam e distribuem os indivíduos (Gaffney \& Mascarenhas 2005/06: 02). Os autores dão especial importância para as formas de vigilância da instituição total sobre o indivíduo:

Inside the stadium, the panoptic mechanism is realized in an intense and hierarchical form. The diverse camera angles capture every movement of the athletes, equally when they are not participating in the game. The same applies to the coaches and referees. Media and fans dominate the visual field. The police forces, for their part, dominate the behavior of the fans. Media personnel have their own spaces, places, and times in which they perform and are contolled by a rigid security system. In synthesis, the sporting event and the stadium acquire a high degree of pre-visibility, are submitted to inumeral rules, a concert of efficient gestures, techniques and moviments, and is a thoroughly realized disciplinary space (Gaffney \& Mascarenhas, 2005/06: 10-11).

Há ainda outros mecanismos de governo tão importantes quanto estes, mas 


\section{Nanduty}

ISSN:2317-8590

exercidos à distância: o econômico, por exemplo. Nos novos estádios brasileiros, os preços dos ingressos aumentaram bruscamente, fator que, supõe-se, deve ter alterado o perfil de classe social de frequentadores das partidas de futebol, assim como algumas de suas práticas enquanto torcedores/espectadores. Os alimentos gourmetizados, os celulares e aplicativos como Instagram, que em nada lembram os rádios a pilha, são uma nova rotina. Estes detalhes, ao que tudo indica, transformam a experiência de frequentar o estádio em algo muito diferente do que aquilo que fora há até alguns anos. Mais do que isso, possivelmente produzem novas formas de governo das torcidas e dos espectadores do futebol.

A este processo, Llopis-Goig (2012) denominou comodificação do futebol. A partir do caso espanhol, o autor afirma que se trata de mudanças no governo dos clubes, agora no modelo de corporações, o crescimento da publicidade, a migração global de jogadores e a fomentação de consumidores (2012: 392). No estudo desse processo histórico em que torcedores deixam de ser pensados como sócios de clubes e passam a ser remodelados enquanto "hiper-consumidores", Llopis-Goig chama atenção para um importante detalhe:

(...) the process of commodification has not affected fans' feelings of identification with their clubs, although it has affected their repertoire of behaviours. A situation of hyper-consumption has been produced, which could be defined as an increase and intensification of the consumption of football information and televised broadcasts, parallel to the increase in football offerings in the media. This hyper-consumption explains the growing personalization of football consumption and an intensification of the entertainment-festive dimension of attending matches at the stadiums (LlopisGoig, 2012: 405).

Poderíamos, deste modo, seguir com a ideia de mudança nos comportamentos e avançar para além da definição do estádio enquanto espaço disciplinar. Ao descrever o processo de ascensão e queda do fosso - uma tecnologia de segregação e confinamento cuja utilidade era separar o público dos jogadores e impedir os primeiros de entrar no campo de jogo - Arlei Damo (2017) afirma que a obsolescência do mesmo seria indicativo do nascimento de novas formas de agenciamento e governo dos públicos. $\mathrm{Na}$ remodelação dos estádios, os torcedores não seriam mais indivíduos que demandam contenção e regulação por parte do Estado. Em suas palavras: 


\section{Nanduty}

O fosso é sem dúvida um dispositivo grotesco, cuja anatomia lembra as trincheiras de guerra. Uma entidade dessa natureza não poderia ser invenção senão do Estado, a instituição responsável pelos negócios da guerra no período moderno - ou ao menos, que detém o seu monopólio. A sua finalidade é escancarada: conter a fúria das massas, dessa gente incivilizada que o próprio Estado alocou nos estádios. O desaparecimento desse dispositivo, como se pode notar na arenização, é também um indicativo de que o Estado já não é mais o agenciador dos espetáculos. Desde que as próprias instituições esportivas chamaram para si a responsabilidade de governar a população que vai aos jogos - e o relatório Taylor é um marco importante dessa transição - trataram de criar outras estratégias de contenção, no que foram auxiliados por experts de diferentes áreas. Segmentaram os espaços para reduzir a mobilidade do público, introduziram câmaras para monitorar o comportamento, colocaram seguranças (privados) dentro de campo e afastaram o público que supostamente necessitava ser contido pelo fosso (Damo, 2017: s/p).

Os novos estádios de futebol, após o processo de arenização, nos obrigam a considerar, no atual momento, a dominância de uma forma bem específica de gerir as pessoas e o espaço, o que pode ser deduzido segundo uma série de normativas e recomendações formalizadas pelas próprias entidades privadas que organizam o evento esportivo (Oliveira Junior, 2017). Parece-me que a vigilância pan-óptica e diversos controles persistem, porém desencoraja-se o confinamento, por exemplo. Na atual governamentalidade, deseja-se o controle de si, isto é, o novo espectador deve ser entendido como sujeito autônomo e capaz de regular seu próprio comportamento. Penso que os problemas da combinação dos governos sobre corpo e população já apareciam em Em defesa da sociedade, quando Foucault argumentava:

Pode-se mesmo dizer que, na maioria dos casos, os mecanismos disciplinares de poder e os mecanismos regulamentadores de poder, os mecanismos disciplinares do corpo e os mecanismos regulamentadores da população são articulados um com o outro. Um ou dois exemplos: examinem, se quiserem, o problema da cidade, ou, mais precisamente, essa disposição espacial pensada, concebida, que é a cidade-modelo, a cidade artificial, a cidade de realidade utópica, tal como não só a sonharam, mas a constituiram efetivamente no século XIX. Examinem algo como a cidade operária. A cidade operária, tal como existe no século XIX, o que é? Vê-se muito bem como ela articula, de certo modo perpendicularmente, mecanismos disciplinares de controle sobre o corpo, sobre os corpos, por sua quadrícula, pelo recorte mesmo da cidade, pela localização das famílias (cada uma numa casa) e dos indivíduos (cada um num cômodo). Recorte, pôr indivíduos em visibilidade, normalização dos comportamentos, espécie de controle policial espontâneo que se exerce assim pela própria disposição espacial da cidade: toda uma série de mecanismos disciplinares que é 


\section{Nanduty}

fácil encontrar na cidade operária. E depois vocês têm toda uma série de mecanismos que são, ao contrário, mecanismos regulamentadores, que incidem sobre a população enquanto tal e que permitem, que induzem comportamentos de poupança, por exemplo, que são vinculados ao hábitat, à locação do hábitat e, eventualmente, à sua compra. Sistemas de seguro-saúde, ou seguro-velhice; regras de higiene que garantem a longevidade ótima da população; pressões que a própria organização da cidade exerce sobre a sua sexualidade, portanto sobre a procriação; as pressões que se exercem sobre a higiene das famílias; os cuidados dispensados às crianças, a escolaridade, etc. Logo, vocês têm mecanismos disciplinares e mecanismos regulamentadores (Foucault, 2010: 211).

Portanto, levando em conta a combinação dos “mecanismos disciplinares” e “reguladores”, é pertinente presumir que os novos estádios não só tenham novos públicos, mas uma ressubjetivação do torcedor ou frequentador do futebol, que somente novas pesquisas poderiam precisar, confirmar ou refutar, considerando, por certo, a persistente variedade de formas de assistir ao jogo mesmo após a arenização.

Tomemos um exemplo no mínimo curioso, ocorrido no Campeonato Brasileiro de 2018. Grêmio FBPA e SC Internacional, os dois principais times de Porto Alegre, se enfrentavam revivendo a histórica rivalidade no Gre-Nal $416^{4}$. O jogo se encaminhava para um empate sem gols, decepcionando a torcida gremista, mandante deste clássico disputado na Arena. Minutos antes do fim, um sinalizador foi arremessado no gramado, interrompendo a partida por alguns instantes. $\mathrm{O}$ artefato foi recolhido pela arbitragem, que fez o registro do evento indesejado na súmula da partida. Situações como essa são prejudiciais ao time local, responsável por dar condições adequadas para o futebol, e normalmente acarretam em punições econômicas ou esportivas, sancionadas pela entidade organizadora do evento, neste caso, a Confederação Brasileira de Futebol. No âmbito esportivo, os clubes são considerados também responsáveis pelo comportamento de sua torcida - quando generalizada - , por isso realizam campanhas recordando que qualquer ação agressiva dos torcedores pode acarretar em prejuízo ao próprio clube. Isso só não ocorre quando o transgressor é identificado individualmente e encaminhado para o Juizado Especial Criminal competente. Nestes casos, a responsabilidade é esvaziada do clube e passa ao indivíduo.

Para tal identificação, os clubes normalmente contam com vigilância através de

Ver sobre em https://www.foxsports.com.br/news/357799-torcedor-do-gremio-joga-sinalizadorno-campo-e-e-agredido-na-arquibancada (Acessado em 29/04/2019). 


\section{Nanduty}

ISSN:2317-8590

câmeras e até mesmo sistema de biometria para alguns setores do estádio. A novidade que o sinalizador arremessado no clássico disputado na Arena do Grêmio aporta é para uma transformação significativa nas formas de controle e vigilância. O pan-óptico não foi necessário para a identificação do torcedor em questão. Antes disso, os demais torcedores do mesmo time o identificaram e o denunciaram. Ele foi contido e ainda agredido até o momento em que os seguranças do estádio chegaram ao local, com o fim de conter o tumulto e encaminhá-lo às devidas instâncias legais.

O arremesso de objetos em direção ao gramado não é novidade: moedas, latas, pilhas, rádios e sapatos faziam parte de um criativo repertório, hoje menos frequente na primeira divisão do futebol brasileiro. As arenas aproximaram fisicamente os públicos do jogo, aumentando seu conforto e melhorando sua visibilidade da partida. Isso foi possível devido à retirada de muitas das barreiras físicas que separavam torcedores e jogadores. Porém, as mudanças não necessariamente puseram fim aos “comportamentos indesejados" . O que, atualmente, o caso do sinalizador no Gre-Nal poderia nos indicar, é a internalização da vigilância e da disciplina, dispensando a presença constante de figuras que servem para estabelecer a norma. Todos os torcedores sabiam que um artefato arremessado traria prejuízos ao clube e que aquela atitude isolada estava fora de contexto. Em outras condições, ou em outras épocas, aquela ação talvez fosse até encorajada. Entretanto, neste novo ambiente, o estádio arenizado, desaprovou-se e reprimiu-se imediatamente o ato, sem necessidade de presença da instituição.

Com isso, não pretendo afirmar que a governamentalidade tomou conta de todos os espaços no futebol e que os torcedores agora são ou devem ser responsáveis por si. Nos anos recentes, algumas pesquisas inclusive têm atestado o surgimento de movimentos contestatórios à comodificação e à arenização do futebol ${ }^{5}$. Na verdade, o arranjo do governo de si parece estar mais presente nas novas arenas, mais em alguns eventos e competições do que em outros. Contudo, a subjetivação de um público com estas características é um dado a ser observado mais de perto, bem como suas relações com outros torcedores, não necessariamente adaptados ou esperados após a arenização.

$5 \quad$ Cf. Lopes \& Hollanda (2017); Santos \& Helal (2016); Santos (2016); Oliveira (2017); Numerato (2014); Merkel (2012). 


\section{Nanduty}

ISSN:2317-8590

É impossível ignorar a heterogeneidade entre os públicos ${ }^{6}$. Os estádios vêm distribuindo suas assistências em setores diferentes, a partir de recortes que poderiam cruzar marcadores de classe, raça e gênero. Um exemplo disso é o das torcidas organizadas que normalmente se territorializam em determinadas áreas do estádio. Estas torcidas não se caracterizam no modelo do torcedor individualizado das arenas e inclusive têm sido a principal oposição ao modelo all-seated, afinal reivindicam setores sem cadeiras, pois sempre assistem aos jogos em pé. Formam grupos que podem superar mais de mil participantes, levam instrumentos musicais, elaboram músicas, bandeiras e faixas.

Por um lado, as torcidas organizadas são normalmente elogiadas devido ao componente festivo de suas performances. Por outro lado, são criticadas pelo envolvimento em brigas com outros grupos organizados ou por protestos violentos contra dirigentes do seu clube. Assim, quando se fala em estádios de futebol e segurança, mais comumente refere-se às torcidas organizadas como um problema, graças ao temor da ocorrência de episódios de violência.

Como ponto de partida, pressuponho que o modelo de arenas ainda comporte uma variedade de públicos que vivem as tecnologias de poder à sua maneira. Em algum sentido, as torcidas organizadas ainda são tratadas dentro da lógica do que Esposito (2008) denomina “paradigma imunitário” . Isto é, são percebidas enquanto agentes patológicos e, apesar das novas arquiteturas, são isoladas, apartadas e confinadas antes e durante as partidas de futebol. Seus deslocamentos pela cidade em dias de jogo envolvem escoltamento e controle policial. Do lado de dentro do estádio, demandam a vigilância de seguranças privados.

Como grupos que, muitas vezes, têm a violência física como uma linguagem importante para o pertencimento ${ }^{7}$, as torcidas organizadas também exercem governos sobre seus integrantes. Há uma série de hierarquias internas, incluindo líderes e subalternos, cuja formação poderá ser demonstrada em pesquisas subsequentes. Do ponto de vista da composição política dos grupos, suponho que, de modo generalizado, existam discrepâncias evidentes. Pela minha experiência prévia nestes estádios, percebo que os torcedores que ingressam nas torcidas organizadas normalmente ocupam papéis

Cf. Giulianotti (2012).

Sobre isso, já há alguns trabalhos de cunho etnográfico. Ver, por exemplo, Garriga (2007). 


\section{Nanduty}

ISSN:2317-8590

inferiores e desempenham tarefas menos nobres. Às vezes seguram bandeiras, dão suporte para que outros possam assistir ao jogo mais de perto, etc. Há, ainda, os casos de participantes menos engajados nas atividades das torcidas, frequentadores ocasionais e simpatizantes que ocupam o mesmo espaço e geralmente atuam junto nas performances musicais ao longo das partidas. Estes, no entanto, não chegam a participar de momentos significativos como excursões, ensaios, reuniões e outros espaços mais restritos.

Para aquela concepção de torcedor individualizado que busca o melhor lugar para acompanhar à partida, a relação de pertencimento não parece fazer muito sentido. Talvez, haveria um caminho para refletir acerca dos torcedores que abdicam de suas “individualidades” para fazer parte da torcida, com base em contribuições de Butler. Para a autora, é impossível escapar às relações de poder, e a sujeição indica "tanto o processo de se tornar subordinado pelo poder quanto o processo de se tornar um sujeito” (Butler 2017: 10). Dessa forma, a subordinação não é oposto da liberdade, mas uma condição da constituição do sujeito.

No mesmo sentido, poderíamos repensar a noção de pessoa que aparece em grupos como estes. Contrariando o postulado do sujeito racional e autônomo do iluminismo ou até mesmo do homo oeconomicus, James Ferguson (2013) sugere ponderar sobre o que denomina “declarações de dependência” . Isto é, casos em que a concepção da pessoa é dada em relações de subordinação, demonstrando formas de pertencimento indesejáveis para uma concepção que opõe liberdade à dependência.

Procurei indicar possibilidades nos estudos sobre os públicos de futebol, nos quais o referencial desenvolvido a partir da noção de biopolítica poderia conduzir a novas interpretações. Acredito que, através de uma abordagem comparativa das transformações, será possível fazer alguns apontamentos, sobretudo no que diz respeito à questão do governo - ou governos - dos torcedores no recente processo de remodelação dos estádios de futebol. Evidentemente, os impactos não se restringem à partida de futebol em si. Eles afetam instituições como os clubes, as cidades que são 


\section{Nanduty}

ISSN:2317-8590

também remodeladas pelo contexto de megaeventos e a subjetividade torcedora. São muitas agências que devem ser consideradas: as tecnologias de informação e comunicação, a atuação do estado através da polícia e da justiça, os diferentes públicos torcedores, as relações políticas nos clubes de futebol, entre outras.

Considerando o caráter ainda incipiente deste ensaio, avalio que novas pesquisas podem vir a confirmar, rejeitar ou reformular muitas das definições buscadas aqui. Por ora, o que parece possível de afirmar sem receio é a existência de diferentes públicos que vivem experiências muito próprias do estádio de futebol. Apesar da comodificação, nem todos parecem dispostos a aderir ao modelo de torcedor individualizado ou clientelizado. Ao mesmo tempo, outro dado a reconhecer é a presença mais constante do governo de si e de instituições mais porosas, que reconfiguram as modalidades de controle.

\section{REFERÊNCIAS BIBLIOGRÁFICAS}

ALABARCES, Pablo. 2012. Crónicas del aguante: fútbol, violencia y política. Buenos Aires: Capital Intelectual.

AVELINO, Nildo. 2016. "Foucault e a racionalidade (neo)liberal". In: Rev. Bras. Cienc. Pol. 21: 227-284.

BUTLER, Judith. 2017. A vida psíquica do poder: teorias da sujeição. Belo Horizonte: Autêntica Editora.

CASTRO, Edgardo. 2009. Vocabulário de Foucault: um percurso pelos seus temas, conceitos e autores. Belo Horizonte: Autêntica Editora.

CORBANEZI, Elton. 2014. "Geoffroy de Lagasnerie: uma polêmica leitura neoliberal de Foucault”. In: Revista Brasileira de Ciências Sociais 29: 195-199.

DAMO, Arlei. 2017. Do fosso ao selfie. In: https://www.ludopedio.com.br/arquibancada/do-fosso-ao-selfie/ (acessado em 30 de abril de 2019).

DELEUZE, Gilles. 1992. “Post-Scriptum sobre as sociedades de controle” . In: DELEUZE, Gilles. Conversações, 1972-1990. São Paulo: Ed. 34.

ESPOSITO, Roberto. 2008. Bios: biopolitics and philosophy. Minneapolis, MN: Minnesota Press.

FERGUSON, James. 2013. "Declarations of dependence: labour, personhood, and welfare in southern Africa” . In: Journal of the Royal Anthropology Institute 19: 223242.

FOUCAULT, Michel. 2008. Nascimento da biopolítica: curso dado no Collège de France (1978-1979). São Paulo: Martins Fontes.

FOUCAULT, Michel. 2010. Em defesa da sociedade: curso no Collège de France (1975-1976). São Paulo: Martins Fontes. 


\section{Nanduty}

ISSN:2317-8590

FOUCAULT, Michel. 2016. “A governamentalidade” . In: FOUCAULT, Michel. Microfísica do poder. Rio de Janeiro: Paz e Terra.

FOUCAULT, Michel. 2017. História da sexualidade 1: a vontade de saber. Rio de Janeiro/São Paulo: Paz e Terra.

FOXSPORTS. Torcedor do Grêmio joga sinalizador no campo e é agredido na arquibancada. In: https://www.foxsports.com.br/news/357799-torcedor-do-gremiojoga-sinalizador-no-campo-e-e-agredido-na-arquibancada (acessado em 30 de abril de 2019).

GAFFNEY, Christopher; MASCARENHAS, Gilmar. 2005/06. "The soccer stadium as a disciplinary space” . In: Esporte e Sociedade 1: 01-16.

GARRIGA ZUCAL, José. 2007. Haciendo amigos a las piñas: violencia y redes sociales en una hinchada de fútbol. Buenos Aires: Prometeo Libros.

GIULIANOTTI, Richard. 2012. "Fanáticos, seguidores, fans e flaneurs: uma taxonomia de identidades do torcedor no futebol". In: Revista História do Esporte 5: 25-46.

LASGASNERIE, Geoffroy de. 2013/14. "Néoliberalisme, théorie politique et pensée critique” . In: Raisons Politiques 52: 63-76.

LLOPIS-GOIG, Ramón. 2012. "From 'sócios' to 'hyper-consumers': an empirical examination of the impact of commodification on Spanish football fans". In: Soccer \& Society 13: 392-408.

LOPES, Felipe. \& Hollanda, Bernardo. 2017. “'Ódio eterno ao futebol moderno': poder, dominação e resistência nas arquibancadas dos estádios da cidade de São Paulo". In: Tempo 24: 206-232.

MERKEL, Udo. 2012. "Football fans and clubs in Germany: conflicts, crises and compromises". In: Soccer \& Society 13: 359-376

NUMERATO, Dino. 2014. "Who says 'No to Modern Football?' Italian supporters, reflexivity, and neo-liberalism". In: Journal of Sport and Social Issues 39: 120-138.

OLIVEIRA JUNIOR, Ricardo. 2017. A reviravolta dos "fanáticos": Arenização, agenciamentos mercadológicos e novos movimentos políticos a partir do Sport Club Internacional. Tese de Doutorado em Antropologia Social, Universidade Federal do Rio Grande do Sul.

SANTOS, Irlan. 2016. "Mercantilização do futebol e movimentos de resistência dos torcedores: histórico, abordagens e experiências brasileiras". In: Esporte e Sociedade 11: 01-18.

SANTOS, Irlan. \& Helal, Ronaldo. 2016. "Do espectador ao militante: a torcida de futebol e a luta pelo direito ao estádio e ao clube". In: Tríade: comunicação, cultura e mídia 4: 53-69.

THE TELEGRAPH. What happened at Hillsborough in 1989?. In: https://www.telegraph.co.uk/news/0/happened-hillsborough-1989/ (acessado em $1^{\mathrm{o}}$ de agosto de 2018). 